\title{
The Amino Acid Composition of Algal Cell Walls
}

\author{
By T. PUNNETT* AND ETHYL C. DERRENBACKER \\ Department of Biology, University of Rochester, New York, U.S.A. \\ and Department of Biology, Temple University, Philadelphia, \\ Pennsylvania, U.S.A.
}

(Received 30 November 1965)

\begin{abstract}
SUMMARY
The cell walls of six different species of algae were prepared in highly purified form and their amino acid and amino sugar contents determined qualitatively. A limited number of ninhydrin-positive components was found, implying that the walls contain peptide rather than protein. In five of the algal walls, those of the Chlorella species, a Scenedesmus and a Lyngbya, there were eight amino acids found in common: aspartic acid, glutamic acid, glycine, alanine, serine, valine, leucine, isoleucine. In addition to these common amino acids, the walls contained sometimes proline or hydroxyproline and different combinations of amino sugar which were characteristic of the species. In the sixth algal wall preparation, that of Nostoc, only five of the eight common amino acids were found along with hydroxyproline. Muramic acid and diaminopimelic acid were found in Lyngbya walls but in none of the others, excepting Nostoc walls which may have contained small amounts of diaminopimelic acid. Carotenoids were found associated with crude wall preparations of some of these algae. The above is taken as evidence for the existence of wall peptide in algae similar to that found in bacteria. This finding strengthens the phylogenetic relationship between the blue-green algae and the other algae, and it raises the possibility that classification of the algae may be aided by knowledge of the chemistry of the wall.
\end{abstract}

\section{INTRODUCTION}

In most investigations of the chemistry of algal cell walls, complex amino acid and carbohydrate patterns have been found and have been ascribed to the existence of protein and mixtures of polysaccharides in the walls. In those investigations the analyses were performed either on whole algae extracted with water and alkali (e.g. Cronshaw, Myers \& Preston, 1958; Iriki \& Miwa, 1960) or on mechanically disrupted organisms washed with water (Northcote, Goulding \& Horne, 1958, 1960). The use of such preparative procedures leaves open the question of whether the walls are intrinsically complex or whether a simpler amino acid and carbohydrate composition is masked by cytoplasmic contamination of the wall preparations. In comparable studies of the walls of bacteria, water washing was seldom adequate to remove such contamination and more drastic procedures had to be adopted (Salton, 1953; Cummins \& Harris, 1956a). In the case of the very complex walls of Gram-negative bacteria, treatment with detergents, phenol and other reagents had

\footnotetext{
* Present address: Department of Biology, Temple University, Philadelphia, Pennsylvania 19122, U.S.A.
} 
to be used to remove some of the wall components and reveal the simpler, underlying mucopeptide (Weidel \& Primosigh, 1957; Mandelstam, 1961).

If algal cell walls are as difficult to purify as bacterial walls, then perhaps some of the algal 'wall proteins' and 'wall polysaccharides' previously described actually arose from contaminating membranes or from insoluble portions of organelles that could not be removed by centrifugal water washing of extracted whole or punctured organisms. In this case, more extensive washing of algal cell-wall preparations might reveal simple amino acid and carbohydrate compositions. The present work was done to see whether this was the case. A preliminary report of the results obtained has appeared elsewhere (Punnett \& Grieg, 1961).

\section{METHODS}

The algae used in this study were obtained from the Algal Culture Collection at Indiana University and are identified by their r.U. culture collection numbers. They were grown in inorganic media with gas phase air $+4 \%(\mathrm{v} / \mathrm{v}) \mathrm{CO}_{2}$ over a fluorescent light source. The culture media had the following compositions (concentrations in $\mathrm{mm}$ unless stated otherwise): for the chlorella species (EmersonChalmers medium) $\mathrm{KH}_{2} \mathrm{PO}_{4} 1 \cdot 5, \mathrm{KH}_{2} \mathrm{PO}_{4} 2 \cdot 5, \mathrm{KNO}_{3} 10, \mathrm{MgSO}_{4} 6, \mathrm{NaCl} \mathrm{0.5}$, $\mathrm{Ca}\left(\mathrm{NO}_{3}\right)_{2} 0 \cdot 5, \mathrm{FeSO}_{4} 20 \mu \mathrm{M} / 1, \mathrm{~A}_{5}, \mathrm{~B}_{9}$ (the $\mathrm{A}_{5}$ and $\mathrm{B}_{9}$ micronutrient solutions described by Brody and Emerson, 1959); for Scenedesmus obliquus (Gaffron medium) $\mathrm{K}_{2} \mathrm{HPO}_{4} \mathrm{l} \cdot 0, \mathrm{~K}_{2} \mathrm{CO}_{3} \mathrm{1} \cdot 0, \mathrm{NH}_{4} \mathrm{NO}_{3} 2 \cdot 5, \mathrm{MgSO}_{4} \mathrm{0} \cdot 2, \mathrm{NaCl} 0 \cdot 15, \mathrm{Ca}\left(\mathrm{NO}_{3}\right)_{2} 0 \cdot 1, \mathrm{FeSO}_{4}$ $20 \mu \mathrm{M} / \mathrm{l}$., $\mathrm{A}_{5} \mathrm{~B}_{9}$; for the lyngbya, anabaena, nostoc species; $\mathrm{KH}_{2} \mathrm{PO}_{4} 1 \cdot 0$, tris $(\mathrm{OH}$ form) 5.0, $\mathrm{Na}_{2} \mathrm{CO}_{3} 15 \cdot 0, \mathrm{KNO}_{3} 10 \cdot 0, \mathrm{MgSO}_{4} 1 \cdot 0, \mathrm{Ca}\left(\mathrm{NO}_{3}\right)_{2} 0 \cdot 3, \mathrm{FeSO}_{4} 20 \mu \mathrm{M} / \mathrm{l} . \mathrm{A}_{5}, \mathrm{~B}_{9}$.

The algae were harvested by centrifugation and washed several times with $0 \cdot 05$ $\mathrm{M}-\mathrm{KCl}$. The washed algae were made to a $50 \%(\mathrm{v} / \mathrm{v})$ or more suspension in water, mixed with three to four weights of glass beads and ground for 15-30 min. in a Virtis homogenizer (Model 23). After the beads settled out, the suspension of broken algae was decanted, the beads washed several times with small samples of distilled water and the washes pooled with the broken algae. This suspension was centrifuged for $10 \mathrm{~min}$. at 8000 to $10,000 \mathrm{~g}$ and the supernatant fluid discarded. This degree of centrifugal force was needed to sediment the cleanest walls. The pellet, which contained some whole algae, the broken algae and other cellular debris, was washed 4 to 8 times with distilled water at $10,000 \mathrm{~g}$. It was then washed with $\mathrm{M}-\mathrm{NaCl} 4$ to 6 times. The wall suspensions were next washed with water and then $0 \cdot 1 \% \mathrm{Na}$ laurylsulphate 2 to 4 times. The detergent was removed by two water washes. This salt and detergent washing cycle was often repeated 3 to 5 times.

Following this treatment, the crude wall preparation was treated in one of two ways. Some samples were extracted with a $1+3$ mixture of $82 \%(w / v)$ formic acid + dimethyl formamide at room temperature for 2-4 $\mathrm{hr}$ and re-extracted several times with this solvent. They were then water washed and fractionated by highspeed centrifugation as described below. Other samples were fractionated directly without the organic solvent extraction. The crude wall preparations were centri-

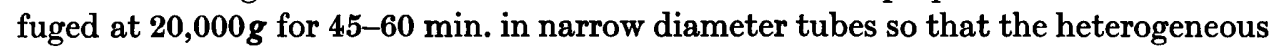
particles were packed into different layers. The top layer was white and loosepacked, while the layers beneath were successively tan, brownish green and green. These layers were removed from the pellet one at a time by gently scraping and 
rinsing with distilled water. Care was taken to prevent mixing of the layers. The separate fractions so obtained were refractionated in the same manner two or three times more. The white pure wall fractions obtained in this way were lyophilized and weighed. The yields varied from 2 to $5 \mathrm{mg}$. dry weight for each $400 \mathrm{mg}$. dry wt. starting material (about $4 \mathrm{~g}$. wet weight). During the preparation, sodium azide was added to the wall suspensions whenever they were left standing in water to prevent bacterial growth (Cummins \& Harris, 1956a).

The criteria for the purity of the wall fractions were: (1) the white colour of the fraction when packed by centrifugation; (2) absence of particulate material inside or around the broken walls when examined microscopically. The brown colour found in some fractions was almost always correlated with the presence of small particles trapped inside the algal walls. These particles showed up especially clearly when viewed with a phase-contrast microscope and in white light phase contrast frequently took on a different hue from that of the walls.

For amino acid analysis, 3-5 mg. samples of the pure walls were hydrolysed in 5-6 N-HCl for $18 \mathrm{hr}$. The hydrolysates were dried in vacuum over $\mathrm{P}_{2} \mathrm{O}_{5}$ and $\mathrm{NaOH}$, taken up in water and re-evaporated several times to remove $\mathrm{HCl}$. Qualitative analysis of the amino acids was done by two dimensional paper chromatography with the solvent system 1 of Redfield (1953) developed by ninhydrin + acetic acid at room temperature. In most cases, the solvent methanol + pyridine + water was used in one dimension and phenol + water (Smith, 1960) in the other, to check the identity of the amino acids in the serine, glycine, alanine region of the chromatogram.

\section{RESULTS}

Of the ten algae investigated in a preliminary survey, four were found to be experimentally unsuitable. When Anabaena variabilis (r.U. 394) was broken, the intracellular contents formed a gel which was not dissolved by any procedure except great dilution which resulted in loss of the walls. The walls of Chlamydomonas reinhardii (I.U. 90) proved to be so fine that the wall fraction was lost when attempts were made to remove other organelles by repeated centrifugation. The crude wall fractions of a spirogyra and a cladophora dissolved and were lost when suspended in sodium laurylsulphate, a reagent found necessary in this study if thoroughly clean walls were to be obtained. These difficulties were not insuperable, but in view of the limited amounts of crude wall fractions available and the abundance of more suitable algae, no further attempts were made to purify the walls of these four algae. The other six algae Chlorella pyrenoidosa (r.u. 252), C. vulgaris (r.u. 398), C. ellipsoidea (I.U. 247), Scenedesmus obliquus (I.U. 393), Lyngbya sp. (I.U. 622) and Nostoc sp. (I.U. 387) yielded purified walls in quantities sufficient for qualitative analysis of their amino acid composition.

\section{Amino acid composition}

In chromatograms of acid hydrolysates of the purified walls, an unmistakable relation between amino acid content and species was found (Table 1). Considering first the four green algae, eight amino acids occurred in high concentration in all four. These were aspartic acid, glutamic acid, glycine, alanine, leucine, isoleucine, valine and, in lesser amount, serine. In addition to the eight common amino acids, 


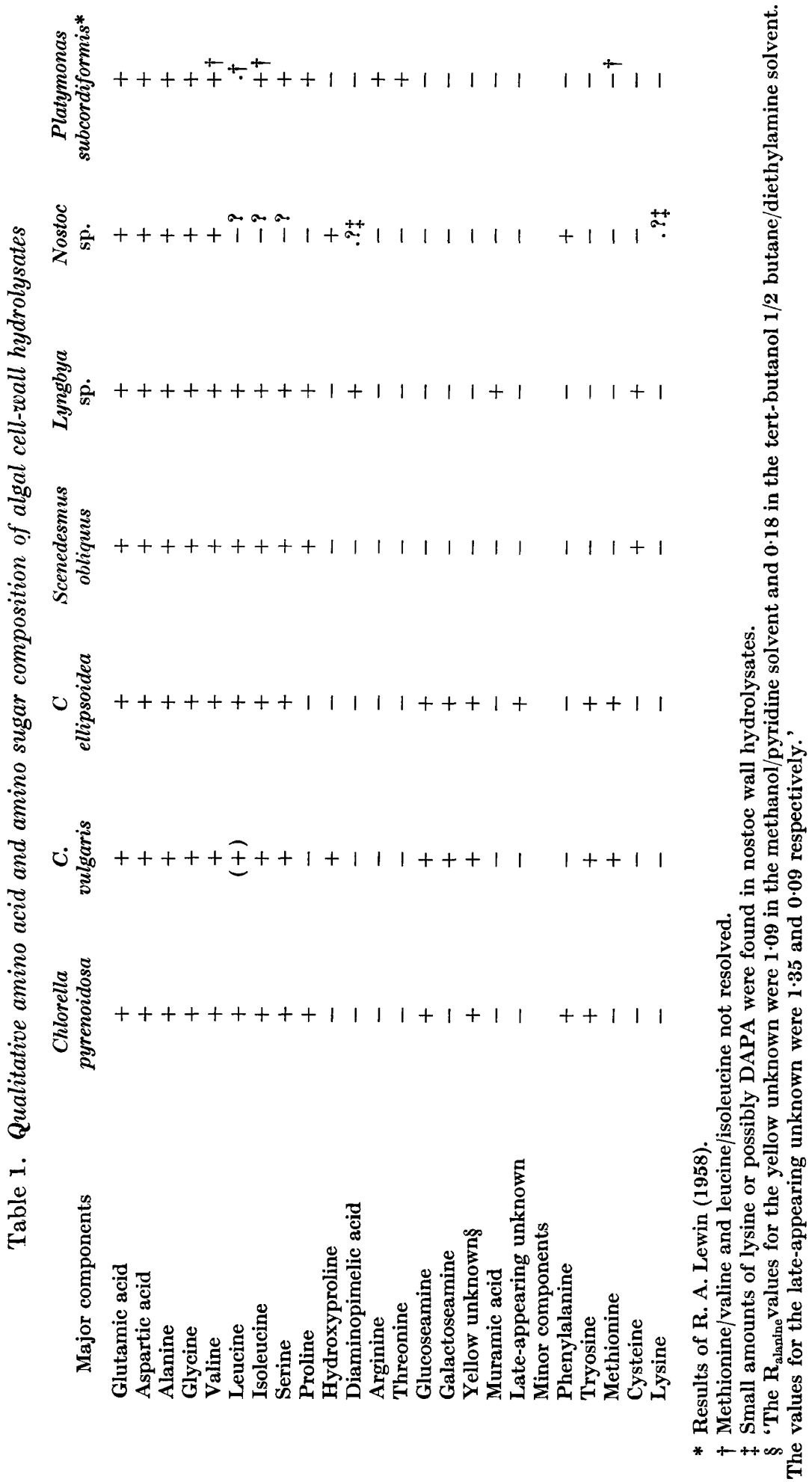


each species had no (Chlorella ellipsoida) or one additional amino acid: C. vulgaris, hydroxyproline; C. pyrenoidosa and Scenedesmus obliquus, proline. The three chlorellas had two or three additional ninhydrin positive components. Two of them were common to the three species: an unknown giving a yellow colour with ninhydrin and glucosamine. The third, galactosamine, was found only in $C$. vulgaris and $C$. ellipsoidea. Another major component of $C$. ellipsoidea walls did not appear on the unheated chromatogram until 4-6 months after the ninhydrin treatment.

Of the two blue-green algae studied, the walls of lyngbya had the same ' $8 \times \mathrm{X}$ ' pattern as found in the green algae. In addition to the 8 common amino acids listed above, these contained diaminopimelic acid (DAPA) and proline. Another ninhydrin positive unknown was found near alanine. This compound was probably muramic acid which has already been reported as a component of the walls of the closely related blue green phormidium (Frank, Lefort \& Martin, 1962), and of microcoleus (Salton, 1964). In one preliminary experiment, the walls of nostoc were found to be different from the others in that they did not have the same $8+\mathrm{X}$ pattern of amino acids. Only six of the 8 'common' amino acids were found: leucine and isoleucine were apparently absent and serine was present in greatly reduced amounts; hydroxyproline was present with traces of lysine (DAPA ?) but muramic acid was definitely not present in this alga.

Also included in Table 1 are the amino acids found in the walls of platymonas by Lewin (1958) because, despite the lack of resolution of leucine/isoleucine and valine/ methionine by the method used, the similarity to the amino acid distribution patterns found in the present work is striking.

The amount of serine found in the wall hydrolysates of all these organisms was always roughly half that of the other major components to judge by the intensity of the colour of the spot on the chromatogram compared with standard chromatograms.

\section{Minor components}

When the amino acids designated 'minor components' in Table 1 were found, they were always present in much smaller amounts than the major components. They were variable constituents of the different wall preparations, both qualitatively and quantitatively, and were sometimes entirely absent. Impure wall preparations were always found to contain these minor components. In one series of experiments, samples of impure wall preparations of scenedesmus and lyngbya were analysed before and after successive washes with formic acid +dimethyl formamide. The major components were qualitatively and quantitatively unaffected by these washings but the minor components were removed. These observations lead to the conclusion that the minor amino acids probably arose from protein contamination and were not part of the wall itself. Critical evidence ruling out the possibility that they were wall components has not yet been obtained.

\section{Pigments}

Carotenoids were associated with walls of several of the algae. This was most easily seen when the preparation procedure was modified as follows. After breakage and extensive water washing, the crude walls were washed with $\mathrm{m}-\mathrm{NaCl}$ and finally with water. At this stage, the wall fraction prepared from Chlorella pyrenoidosa and Scenedesmus obliquus were pink while the lyngbya and nostoc preparations were 
orange. These pigments were removed from nostoc and lyngbya walls by shaking them either with $0 \cdot 1 \%$ sodium laurylsulphate or formic acid + dimethylformamide. Chlorella pyrenoidosa walls were not rendered completely colourless by the detergent treatment but the residual pigment was removed with formic acid + formamide or phenol. The crude wall fraction prepared from C. ellipsoidea, the smallest of this group of algae, was usually pale green, probably because of chloroplast fragment inclusions which were not removed by simple washing.

Preliminary evidence about the nature of these carotenoid pigments was obtained from reversed phase paper chromatography (Angapindee, Silberman, Tantivatana \& Kaplan, 1958). The pink pigment from Chlorella pyrenoidosa and the orange nostoc pigment appeared to be carotenols, while the pink scenedesmus pigment and the orange lyngbya pigment were carotenes. This latter orange pigment changed to a pink carotenol during the running of the chromatogram. The only absorption spectra determined were those of the nostoc carotenol which had a single symmetrical band at $467-470 \mathrm{~m} \mu$ in methanol, and the lyngbya carotene which had peaks at 442, 470 and $500 \mathrm{~m} \mu$ in methanol.

These pigments do not seem to have originated from the chloroplast or photosynthetic lamellae. In one experiment, the $10,000 \mathrm{~g}$ supernatant fluid from lyngbya was extracted and the pigments chromatographed and compared to the wall pigment. The pigments from the photosynthetic lamellae were chromatographically different from the corresponding wall pigments.

\section{DISCUSSION}

The results obtained in this work of the amino acids found in algal cell walls differ substantially from those obtained in earlier studies. The reason for this difference was probably the preparative technique used, in particular the washing with $\mathrm{M}-\mathrm{NaCl}$, which presumably removed nucleoproteins, and with detergent which removed adsorbed protein. Washing these walls with water alone did not yield clean preparations. Another significant difference in preparation was the removal of walls containing contaminating inclusions by centrifugal layering, a technique described by Miller \& Phaff (1958). Unless both these procedures were used, the amino acid pattern obtained showed the degree of complexity expected of a protein hydrolysate.

Because of the relatively simple amino acid composition found in thoroughly washed algal walls, it is clear that they contain peptide but do not contain protein. Some protein was found adsorbed to water-washed walls, as already suggested by Northcote (1963), but it was removed by treatment not likely to break covalent bonds. By contrast, the limited numbers of amino acids found in the walls resisted extraction with detergent, phenol and formic acid + dimethylformamide and were undoubtedly covalently bonded. Simple amino acid compositions such as these were reported previously for walls of platymonas released during cell division (Lewin, 1958).

It should be noted that these procedures yielded wall preparations which were analogous to those of Cummins \& Harris (1956a) in that all easily soluble constituents were removed and only the tough, insoluble wall fraction was analysed. The efforts to remove contaminating membranes and organelles may also have 
removed loosely bound components of the envelope, such as an outer slime layer. For this reason, the thoroughly washed material which we define as the wall of the alga may represent something less than the complete envelope of the organism.

The existence of simple amino acid patterns in cell walls has thus been extended from Gram-positive bacteria (Salton, 1953) to Gram-negative bacteria (Weidel \& Primosigh, 1957) and actinomycetes (Cummins \& Harris, 1956b) to unicellular and filamentous algae. It is tempting to speculate that purified walls of yeasts and fungi prepared in the same way will also be found to possess simple amino acid patterns. In this regard, the amino acid content of the walls of trigonopsis reported by SentheShanmuganathan \& Nickerson (1962) were similar to those reported here, in that nine or ten amino acids were present. In addition, Northcote \& Horne (1952) found only six amino acids in a saccharomyces wall preparation. These latter results may have been due to incomplete hydrolysis, however, because in later reports from the same laboratory (Korn \& Northcote, 1960) 18 to 20 amino acids are reported in yeast walls. Protein was found by Dyke (1964) in nadsonia wall preparations which had been washed with dilute $\mathrm{NaCl}$, which does not dissolve nucleoproteins, but not with detergent. These walls were prepared in such a manner that they would still possess their mannan-protein complex and, in addition, may have had some cytoplasmic membrane contamination. Dyke's experimental criteria for lack of cytoplasmic contamination depended on two assumptions; that $0 \cdot 155 \mathrm{M}$ $\mathrm{NaCl}$ removed cytoplasmic protein and that added cytoplasmic protein was in equilibrium with broken cell walls. The first assumption would not have been valid if nadsonia walls are as difficult to purify as algal walls and the second assumption is not likely to have been correct because the walls of the freshly broken cells must already have had membranes tightly adsorbed to them. Since these are among the most extensively washed yeast walls that have been analysed, it is clear that a simple amino acid pattern will not be found in yeasts, if it exists, unless more drastic procedures are used to purify them. The amino acid composition of yeast walls will be further complicated in those many cases in which protein-polysaccharide complexes (Falcone \& Nickerson, 1956) or enzymes (Wilkes \& Palmer, 1932) are located in the wall itself.

The pattern of the distribution of amino acids in algal walls was surprisingly regular. The finding that eight amino acids were common to three chlorella species, a scenedesmus and a lyngbya is reminiscent of the situation found in the Gramnegative bacteria in which all genera have the same amino acids in the walls. The distribution of amino acids in algal walls is also similar to that found in the walls of Gram-positive bacteria in that the amino sugars and the amino acids other than the common eight were characteristic of genus and species. It may be that there is a common basal structure in the walls of algae, except for some blue-green algae (see below), as has been proposed for bacteria (Work, 1957). The hope that the minor variations in this regular pattern can be used as an aid in classifying the algae is premature, because examples of only five or six species have been studied. Furthermore, the only amino acids found so far, in addition to the common eight, have been proline and hydroxyproline: enough to distinguish only four species. Lewin's finding of arginine and threonine in platymonas walls (1958) suggests that other patterns will be found.

The failure to find diaminopimelic acid (DAPA) in the chlorella species was rather 
surprising in light of the report of its presence in Chlorella ellipsoidea (Fujiwara \& Akabori, 1454) which was confirmed by Hoare \& Work (1957). Perhaps the DAPA is present in chlorella only as an intermediate in the biosynthesis of lysine (Vogel 1959) rather than as a wall component. The contrast between the unusual amino acid distribution and the presence of unknowns reported in this study and the conventional distribution found by Fowden (1954) and by Wagner (1962) in their studies of algal amino acids was to be expected, however, because these authors examined the extractable amino acids in the algae, and in some instances discarded the wall fraction.

The two blue-green algae examined have already provided evidence of heterogeneity even though the nostoc results are preliminary. DAPA, muramic acid and the common eight amino acids were present in lyngbya, but muramic acid was not found in nostoc. Nostoc did contain proline and traces of lysine or possibly DAPA while serine, leucine and isoleucine appeared to be missing from the common eight. The absence of muramic acid and possibly DAPA from nostoc distinguishes this organism from the other blue-green algae which have been examined. The significance of this finding, if confirmed, is that the phylogenetic relation between the blue-green algae and the bacteria is not so clear and simple as has been claimed. When first DAPA (Work \& Dewey, 1953) and then muramic acid (Frank et al. 1962) were found in blue-green algae, these results were taken as confirming the proposed close phylogenetic relation between these groups. The earlier arguments in favour of this relation used by Stanier \& Van Niel (1941) were that in both groups there is: (1) lack of organized nuclei; (2) lack of chloroplasts; (3) lack of sexual reproduction. The opposite point of view was presented by Pringsheim (1949) who pointed out that the bacteria and the blue-green algae differ; (1) morphologically (2) in photosynthetic pigments; (3) cytologically; (4) in not showing any striking physiological similarities; (5) in modes of locomotion. Many of the arguments supporting both sides of this question must be modified because of recent developments, especially in the areas of sexual reproduction, cytological fine structure and mechanism of photosynthesis. On balance, recent investigations, with the possible exception of the studies of cell walls, have tended to emphasize the differences between the two groups. The finding in the present work that muramic acid and DAPA are probably absent from the walls of some blue-green algae weakens the argument for close relationship based on cell-wall chemistry. Certainly the flat statement that the blue-green algae stem directly from a bacterial line (Frank et al. 1962) is too strong. The blue-green algae are undoubtedly transition organisms, but they have a closer relation to the other oxygen-evolving photosynthetic algae than they do to bacteria.

The carotenoids found in the crude wall preparations of algae most likely originated in the limiting membrane. That they did not come from the chloroplasts was shown by the evidence given above. They were associated with the walls during the early stages of fractionation and were removed by the detergent wash or by phenol treatment. This conclusion is tentative, however, because there is no way to rule out the possibility of the adsorption of other pigmented organelles to the crude walls. The association of pigments with cell walls of other organisms is known from other studies (Mason \& Powelson, 1958; Salton, 1960). The significance of this pigmented layer around the periphery of some algae is that the photosynthetic action 
spectra of these organisms will be depressed in the region of carotenoid absorption. Such depressions have often been reported but have been ascribed to the low photosynthetic efficiency of the carotenoids in the chloroplast. This conclusion may have to be modified in cases in which algae with pigmented walls were used. Significantly, the strain of Chlorella pyrenoidosa analysed was very possibly Emerson's strain 3. Unfortunately, there is no evidence from this study which allows an estimation of the proportion of total carotenoids found in the membrane or the absorption it causes.

There are many questions left unanswered in this initial study: the nature of the sugars in the walls, the nature of the unknowns, the configuration of the amino acids and their linkages to the rest of the wall and the overall amino acid and carbohydrate distributions in other algal genera. Until methods for the preparation of larger amounts of pure material are developed, however, progress will be slow.

This work was supported by U.S. Public Health Service Research Grants GM 08092-03 and GM 119705-01 from the National Institute of General Medical Sciences.

\section{REFERENCES}

Angapindee, A., Silberman, P., Tantivatana, P. \& Kaplan, I. R. (1958). The separation of chlorophylls by paper and cellulose column chromatography. Arch. Biochem. Biophys. 75,56 .

Brody, M. \& Emerson, R. (1959). The effect of wavelength and intensity of light on the proportion of pigments in Porphyridium cruentum. Am. J. Bot. 46, 433.

Cronshaw, J., Myers, A. \& Preston, R. D. (1958). A chemical and physical investigation of the cell walls of some marine algae. Biochim. biophys. Acta, 27, 89.

Cummins, C. S. \& Harris, H. (1956a). The chemical composition of the cell wall in some Gram-positive bacteria and its possible value as a taxonomic characteristic. J. gen. Microbiol. 14, 583.

Cummins, C. S. \& Harris, H. (1956b). A comparison of cell wall composition in Nocardia, Actinomyces, Mycobacterium and Propionobacterium. J. gen. Microbiol. 15, ix.

Dyke, K. G. H. (1964). The chemical composition of the cell wall of the yeast Nadsonia elongata. Biochim. biophys. Acta, 82, 374.

Falcone, G. \& Nickerson, W. J. (1956). Cell wall mannan-protein of baker's yeast. Science, 124, 272.

Fowden, L. (1954). A comparison of the compositions of some algal proteins. Ann. Bot., N.S. $18,257$.

Frank, H., Lefort, M. \& Martin, H. H. (1962). Elektronenoptische und chemische Untersuchungen an Zellwänden der Blaualge Phormidium uncinatum. Z. Natur. 17b, 262.

Fujiwara, T. \& Akabori, S. (1954). $\alpha, \alpha^{\prime}$-Diaminopimelic acid in Chlorella ellipsoidea. Jap. J. Chem. 75, 990.

HOARE, D. \& WoRK, E. (1957). The stereoisomers of $\alpha, \epsilon$-diaminopimelic acid. Biochem. $J$. 65,441 .

IrIKI, Y. \& Mrwi, T. (1960). Chemical nature of the cell wall of the green algae, Codium, Acetabularia and Halicoryne. Nature, Lond. 185, 178.

Korn, E. D. \& Nonthcote, D. H. (1960). Physical and chemical properties of polysaccharides and glycoproteins of the yeast cell wall. Biochem. J. 75, 12.

Lewin, R. (1958). The cell walls of Platymonas. J. gen. Microbiol. 19, 87.

Mandelstam, J. (1961). Isolation of lysozyme-soluble mucopeptides from the cell walls of $E$. coli. Nature, Lond. $180,855$.

Mason, D. J. \& Powelson, D. (1958). The cell wall of Myxococcus xanthus. Biochim. biophys. Acta, 29, 1.

Miller, M. W. \& Phaff, H. J. (1958). On the cell wall composition of the apiculate yeasts. Antonie van Leeurvenhoek, 24, 225. 
NoRThCote, D. H. (1963). The Structure and Function of the Membranes and Surfaces of Cells, 1st ed., Cambridge University Press.

Northcote, D. H. \& HoRne, R. W. (1952). The chemical composition and structure of the yeast cell wall. Biochem. J. 51, 232.

Northcote, D. H., Goulding, K. J. \& Horne, R. W. (1958). The chemical composition and structure of the cell wall of Chlorella pyrenoidosa. Biochem. J. 70, 391.

Northcote, D. H., Goulding, K. J. \& Horne, R. W. (1960). The chemical composition and structure of the cell wall of Hydrodictyon africanum Yaman. Biochem. J. 77, 503.

Pringsheim, E. G. (1949). The relationship between bacteria and myxophyceae. Bact. Rev. 13, 47.

Punnetr, T. \& Grieg, E. C. (1961). The chemical composition of algal cell walls. Plant Physiol. 36 (suppl. xxxvi).

Redfield, R. R. (1953). Two-dimensional paper chromatographic systems with high resolving power for amino acids. Biochim. biophys. Acta, 10, 344 .

Salton, M. R. J. (1953). Studies of the bacterial cell wall. IV. The composition of the cell walls of some Gram-positive and Gram-negative bacteria. Biochim. biophys. Acta, 10, 512.

Salton, M. R. J. (1960). Microbiological Cell Walls, 1st ed. New York: Wiley.

Salton, M. R. J. (1964). The Bacterial Cell Wall, 1st ed. Amsterdam: Elsevier.

SentheShanmuganathan, S. \& Nickerson, W. J. (1962). Composition of cells and cell walls of triangular and ellipsoidal forms of Trigonopsis variabilis. J. gen. Microbiol. 27, 451.

Smrтr, I. (1960). Chromatographic and electrophoretic techniques, 2nd ed. London: Heinemann.

Stanier, R. Y. \& van Niel, C. B. (1941). The main outlines of bacterial classification. J. Bact. 42, 437.

VogeL, H. J. (1959). Lysine biosynthesis in Chlorella and Euglena: phylogenetic significance. Biochim. biophys. Acta, 34, 282.

WAGNER, M. (1962). Vergleichende Untersuchungen über das Vorkommen von freien und gebunden Aminosäuren in Algen und Pilzen. Zentbl. Bakt.ParasitKde. II, 115, 50.

Weidel, W. \& Primosigh, J. (1957). Die gemeinsame Wurzel der Lyse von E. coli durch Penicillin oder durch Phagen. Z. Natur. 12b, 421.

Wilkes, B. G. \& Palmer, E. T. (1932). The similarity of the kinetics of invertase action in vivo and in vitro. II. J. gen. Physiol. 16, 233.

Work, E. (1957). Biochemistry of the bacterial cell wall. Nature, Lond. 179, 841.

Wonk, E. \& DeweY, D. L. (1953). The distribution of $\alpha, \epsilon$-diaminopimelic acid among various micro-organisms. J. gen. Microbiol. 9, 394. 